\title{
ANÁLISE DIALÓGICA DE MARIA DA VILA MATILDE: A CANÇÃO NO EMBATE CONTRA A VIOLÊNCIA DE GÊNERO*
}

\author{
Mayra Pinto ${ }^{1}$ \\ Rainy Sena dos Santos ${ }^{2}$
}

RESUMO: O presente trabalho analisa a canção Maria da Vila Matilde, de Douglas Germano, interpretada por Elza Soares, sob a perspectiva da Teoria dialógica do discurso. Em tempos em que o discurso feminista está ganhando força (boa parte por conta das redes sociais) e que a luta contra o machismo vem crescendo cada vez mais, o discurso artístico pode contribuir para fortalecer uma atitude de empoderamento e de enfrentamento dessa questão. $\mathrm{Na}$ análise, observa-se quais valores sociais e categorias discursivas constituem um discurso de denúncia da violência doméstica contra a mulher. A interpretação da cantora é analisada em sua clave irônica de modo a observar como essa categoria discursiva pode estabelecer os diversos matizes que constroem axiologicamente o tom de confronto do eu lírico feminino com os valores machistas.

PALAVRAS-CHAVE: Valorações sociais. Entonação. Ironia. Canção.

ABSTRACT: This work analyses Douglas Germano's song "Maria da Vila Matilde", sung by Elza Soares, from the perspective of the dialogical discourse theory. In a moment such as this, in which the feminist discourse is strengthening (in part, due to the social medias), and the fight against chauvinism is growing, the artistic discourse can contribute to strengthen an empowering attitude towards the confrontation of such questions. In the song analysis, we can observe which social values and discursive categories constitute a domestic violence denunciation discourse. Elza Soares' singing of the song is analyzed in its ironic key in order to observe how this discursive category can establish several tinctures which create, axiologically, the confrontational tone of the female lyrical voice against chauvinist values.

KEYWORDS: Social validation; Intonation, Irony, Song.

\section{Introdução}

A arte é também eminentemente social.

Volochínov (2013)

Em tempos em que o discurso feminista está ganhando força (boa parte por conta das redes sociais) e que a luta contra o machismo vem crescendo cada vez mais, canções como Maria da Vila Matilde, composta por Douglas Germano e interpretada por Elza

\footnotetext{
* Este artigo é parte da pesquisa desenvolvida no Projeto de Iniciação Científica intitulado "Análise de canções do álbum 'A mulher do fim do mundo', de Elza Soares, sob a perspectiva da teoria do humor e da teoria dialógica do discurso", que se vincula à linha de pesquisa Teoria Bakhtiniana do Grupo de Estudos da Linguagem do Instituto Federal de São Paulo - GELIFSP.

${ }^{1}$ Professora Doutora do Instituto Federal de Educação, Ciência e Tecnologia de São Paulo (IFSP-SPO), São Paulo, SP, Brasil. Coordena o Grupo de Estudos da Linguagem do Instituto Federal de São Paulo GELIFSP. Endereço eletrônico: mayrapinto@ifsp.edu.br.

${ }^{2}$ Graduanda em Letras pelo Instituto Federal de Educação, Ciência e Tecnologia de São Paulo (IFSP-SPO), São Paulo, SP, Brasil. Endereço eletrônico: rainy.sena@aluno.ifsp.edu.br.
} 
Soares, parte do CD "A mulher do fim do mundo", podem contribuir para fortalecer uma atitude de empoderamento principalmente por ser cantada na voz de uma mulher que ecoa o grito de socorro de tantas outras.

Segundo o Mapa da Violência 2015: Homicídio de mulheres no Brasil (WAISELFISZ, 2015), o Brasil é o quinto país com maior índice de violência contra mulheres (o primeiro é El Salvador, seguido respectivamente por Colômbia, Guatemala e Rússia), aproximadamente 13 mulheres são mortas por dia em nosso país. O Mapa revela ainda que os homicídios contra mulheres brancas, em dez anos (2003 a 2013), diminuíram 9,8\%, enquanto homicídios contra mulheres negras aumentaram $54,2 \%$, no mesmo período. Não queremos, nem poderíamos utilizar esses dados para quantificar ou mesmo para qualificar o sofrimento e a dor entre as mulheres, sabemos que cada pessoa é única, logo, suas vivências são específicas. Dados como esses são importantes, pois nos ajudam a pensar e enxergar como as opressões e as violências de gênero estão estruturadas. Quando dizemos que mulheres pretas sofrem mais assassinatos que mulheres brancas não estamos dizendo que uma sofre mais que a outra, essa seria uma análise individual imprecisa, leviana e injusta. $\mathrm{O}$ que essa pesquisa nos mostra é como o racismo e as desigualdades sociais atuam e corroboram diretamente com a violência de gênero.

Nascida e criada nas periferias do Rio de Janeiro, Elza Soares conhece bem as dores de ser mulher, preta, periférica e mãe. Aos 13 anos, quando levava café para seu pai, avistou um louva-deus (inseto pelo qual sempre teve grande apreço pelo som que emite) e resolveu pegá-lo. Ao observá-la entrar no mato, um rapaz, poucos anos mais velho, resolve segui-la para ver o que estava acontecendo, chegando até o local, Elza derrama o café e se desentende com o rapaz. No meio da briga, o pai de Elza Soares aparece e pensando que os dois estavam tendo um caso, ordena que se casem. Um ano depois do casamento, Elza tem seu primeiro filho. Alguns anos mais tarde, decide participar do programa de talentos de Ary Barroso, pois, depois de ter perdido dois filhos, essa foi a única maneira que encontrou de conseguir dinheiro a fim de comprar os remédios para salvar seu primogênito que estava ficando cada vez mais doente (CAMARGO, 2018).

Em seu programa Calouros em Desfile, Ary Barroso dava oportunidade para pessoas das classes populares mostrarem suas qualidades artísticas, caso não atendessem as expectativas, eram humilhadas pelo apresentador, mas se fizessem uma boa 
apresentação, tinham uma carreira garantida, foi o que aconteceu com Elza Soares. Em entrevista ao programa Roda Viva, em setembro de 2002, Elza Soares conta que no dia em que fez o teste para o programa, foi alertada de que teria de "ir bonita" no dia do programa. Sua família, no entanto, não tinha televisão (raridade naquela época), tampouco contato com a elite carioca, logo, Elza não sabia o que seria "ir bonita". Então, ao subir ao palco trajando o vestido de sua mãe, que pesava 30 quilos a mais, ajustado ao seu corpo por grampos, a plateia e o apresentador começaram a debochar da cantora. É nesse momento que acontece o inesquecível diálogo abaixo, transcrito da supracitada entrevista:

\section{Ary Barroso:}

- O que você veio fazer aqui?

Elza Soares:

- Seu Ary, eu acho que aqui a gente canta, né?

- E quem disse que você canta?

- Eu canto.

- Então me faz o favor e me diga de que planeta você veio?

-Do mesmo planeta seu, seu Ary.

- E qual é o meu planeta?

- Planeta fome.

A cantora conta que ao falar isso, todos os presentes, inclusive o apresentador, sentiram-se constrangidos e sentaram-se para assisti-la. Após sua apresentação, Ary Barroso afirma "Aqui nasce mais uma estrela", consagrando a carreira de Elza Soares, que muito inocente na época, não imaginava tudo o que estaria por vir.

Aos 21 anos, quando fica viúva de seu primeiro marido, Elza já havia dado à luz seis filhos e perdido dois para a desnutrição. Aos 32, conheceu o jogador de futebol Garrincha, com quem teve um relacionamento conturbado durante 17 anos $^{3}$. Apesar de todas as dificuldades de cor, gênero e status social, Elza conseguiu se sobressair com sua voz potente, seu timbre único e suas interpretações marcantes, que lhe renderam prêmios como o de "Melhor cantora do milênio" pela BBC, "Melhor disco de 2016", pelo Grammy e "Personalidade do ano 2016" pela Bravo.

\footnotetext{
${ }^{3}$ Em 1962, Elza Soares se envolveu em um relacionamento com Mané Garrincha. Por ele ser casado, a cantora sofreu grande preconceito por parte da sociedade e viu a vendagem de seus discos decair. $\mathrm{O}$ relacionamento dos dois foi marcado por constantes brigas, boa parte, por conta do problema com álcool do jogador. Até que um dia, em completo estado de embriaguez, Garrincha agride Elza fisicamente e ela o abandona. Um ano após o divórcio, Mané Garrincha morre em decorrência do alcoolismo.
} 
Em “A mulher do fim do mundo", lançado em 2015, a cantora sintetiza as vozes da periferia, as vozes dos marginalizados, sua própria voz e suas vivências. O disco começa com Coração do mar, poema de Oswald Andrade, que traz as vozes da África e o coração dos marinheiros dos cantos da umbanda. Assim, à capela, Elza anuncia seu disco: como um “navio humano, quente, negreiro do mangue". É o que se ouve a seguir: um CD quente, repleto de negritude, repleto do humano.

Em A mulher do fim do mundo, música homônima ao $\mathrm{CD}$, que ganhou videoclipe em março de 2017, é como se estivéssemos diante de sua própria história: ouvimos o canto da mulher preta solitária, que se entrega a um desfile de carnaval, deixando suas dores, suas falas e suas opiniões na avenida, como se personagem e intérprete se fundissem, pedindo em uma só voz que a deixem “cantar até o fimm”. E nas 9 músicas que se seguem (Maria da Vila Matilde, Luz Vermelha, Pra fuder, Benedita, Firmeza?!, Dança, O canal, Solto e Comigo) Elza traz o cenário das periferias, das quebradas, o empoderamento da mulher negra, o crime, o sexo, a transexualidade, o querer viver mesmo depois da morte, as resistências e termina cantando saudade e eterna gratidão à sua mãe.

Tendo em vista a grande contribuição de Elza Soares para o cenário musical brasileiro e a importância de debater um assunto tão sério quanto a violência de gênero, este artigo analisa, com base na Teoria Dialógica do Discurso, a canção Maria da Vila Matilde a fim de verificar quais valores sociais estão sendo retratados na canção e, por meio da entonação, qual a posição axiológica do eu-lírico.

\section{Qual o tom da denúncia?}

\section{MARIA DA VILA MATILDE, de Douglas Germano}

Cadê meu celular?

Eu vou ligar pro 180

Vou entregar teu nome

E explicar meu endereço

Aqui você não entra mais

Eu digo que não te conheço

E jogo água fervendo

Se você se aventurar

Eu solto o cachorro

E, apontando pra você

Eu grito: péguix guix guix guix

Eu quero ver 
PERcursos Linguísticos • Vitória (ES) •v. 10 •n. 25 • 2020 • ISSN: 2236-2592 •

Dossiê: Discursos de resistência e corpos (re)existentes

Você pular, você correr

$\mathrm{Na}$ frente dos vizinhos

Cê vai se arrepender de levantar a mão pra mim

E quando o samango chegar

Eu mostro o roxo no meu braço

Entrego teu baralho

Teu bloco de pule

Teu dado chumbado

Ponho água no bule

Passo e ainda ofereço um cafezim

Cê vai se arrepender de levantar a mão pra mim

E quando tua mãe ligar

Eu capricho no esculacho

Digo que é mimado

Que é cheio de dengo

Mal acostumado

Tem nada no quengo

Deita, vira e dorme rapidinho

Você vai se arrepender de levantar a mão pra mim

Cê vai se arrepender de levantar a mão pra mim

Cê vai se arrepender de levantar a mão pra mim

Cê vai se arrepender de levantar a mão pra mim

Cê vai se arrepender de levantar a mão pra mim

Mão, cheia de dedo

Dedo, cheio de unha suja

E pra cima de mim? Pra cima de moi? Jamais, mané!

Cê vai se arrepender de levantar a mão pra mim

Em “A palavra na vida e a palavra na poesia” (2013), Valentin Volochínov afirma que é um erro analisar uma obra literária apenas de um ponto de vista, somente pela estrutura da obra ou só pela parte social. Defende que os discursos poético e cotidiano estão diretamente ligados, logo, é preciso analisá-los em conjunto, pois o discurso poético sintetiza o discurso do cotidiano, provocando efeitos de sentido a partir da ideologia do autor. Em Maria da Vila Matilde, encontramos um discurso poético constituído por várias vozes do cotidiano: uma voz popular que se enuncia com palavras como "quengo", "samango" e "cafezim", por exemplo; uma voz oprimida, a das mulheres que sofrem o machismo estrutural de nossa sociedade, mas também vitoriosa, quando enfatiza que as mulheres podem não ser mais submissas e subservientes, dado que hoje há um poder público que reconhece sua necessidade de proteção para se defender da violência masculina. Volochínov (2013) diz ainda que o discurso é constituído por valorações sociais. Na canção de Douglas Germano, por exemplo, encontramos um discurso 
revelador de valores conflitantes nas relações amorosas: há uma voz de denúncia e combate da violência doméstica que deixa subentender o fim da submissão ao gesto machista: "Cê vai se arrepender de levantar a mão pra mim".

Segundo a teoria construída por Volochínov (2013), é possível identificar os valores subentendidos nos discursos por meio de três aspectos: valorações sociais, entonação e contexto. Logo, há uma relação entre nós (ouvintes) e a intérprete (enunciador), pois vivenciamos, de uma forma ou de outra, o tema retratado na obra, o que possibilita que entendamos o dito e o não dito da canção. A entonação, uma das categorias que constituem a construção da valoração social no processo de interação (e entendimento) entre o falante e seu público, permite perceber intenções ou sentimentos, que não são verbalizados, por meio do tom da voz, gestos corporais e expressões faciais, por exemplo. Nas obras escritas a entonação é marcada pela escolha do vocabulário, figuras de linguagem, sintaxe e pelo ritmo que o autor emprega ao seu texto.

Em Maria da Vila Matilde, por se tratar de uma canção, a entonação pode ser percebida em vários aspectos: no texto e na entonação que a intérprete escolhe para cantar, assim como na melodia, harmonia e arranjo da música. A canção é iniciada com um sample - som grave e constante que faz a marcação do tempo da música. Em seguida, ouvimos a voz de Elza Soares, com uma entonação firme e séria, perguntar onde está seu celular, pois ligará para o 180, número da Central de Atendimento à Mulher em Situação de Violência, para denunciar seu companheiro por agressão física. Na primeira estrofe, começa a ser construída a imagem de uma mulher segura, consciente, que não está mais sozinha como em tempos remotos, quando apenas ficava em casa à mercê do marido. Agora, amparada pela lei, ganha força para enfrentar seu agressor ou mesmo para simplesmente não aceitar de maneira submissa as violências domésticas que por muito tempo foram naturalizadas como "briga de casal". Maria da Vila Matilde, personagem da canção, além de denunciar seu agressor para o 180, também ameaça revidar seus ataques jogando-lhe "água fervendo" caso "se aventure" a agredi-la.

A interpretação de Elza Soares, somada ao grave do sample, marca o tom sério da primeira estrofe que, embora se repita mais duas vezes durante a canção, se diferencia das demais por estar anunciando que tal situação não se repetirá ou mesmo que jamais chegará a acontecer. Embora os verbos estejam no futuro, indicando ações que provavelmente aconteçam, a entonação usada por Elza Soares é contundente e não deixa espaço para que duvidem de sua palavra. 
Recuperando o conceito de entonação elaborado por Valentin Volochínov (2013), observamos que é a entonação de Elza Soares que nos possibilita reconhecer nessa estrofe o tom mais sério e pungente, sem que, para isso, tenha sido preciso a verbalização de um alerta prévio. Por se tratar de canção, o tom sério é corroborado por outro elemento: o sample. A adição de tal elemento como marcação do tempo da canção faz toda diferença no arranjo, funcionando como um lembrete de que apesar de ser um samba que constrói imagens cômicas, esse é um humor que não acha graça no assunto abordado, a violência doméstica.

A passagem para a segunda estrofe - que completa o estribilho da canção - se dá em tom levemente diferenciado. Para completar a advertência de que seu agressor não entrará mais em sua casa, a personagem introduz imagens cômicas, situações constrangedoras que poderão acontecer com seu agressor: "Eu solto o cachorro/ E apontando pra você/ Eu grito: péguix/ Eu quero ver/ Você pular, você correr/ Na frente dos vizin". Socialmente, a imagem de um homem fugindo de um cachorro é motivo de risos e zombaria, principalmente porque, em uma sociedade patriarcal, espera-se que esse homem, atendendo às expectativas de gênero, cumpra seu papel social de "macho" e enfrente a situação demonstrando força física e bravura. Tais valores sociais são reforçados no verso "na frente dos vizin", onde fica explícito na canção o ideário popular de que o homem nunca deve demonstrar fraqueza e agora a ameaça além de física passa a ser moral, pois diante dos vizinhos esse homem seria ridicularizado, passando a ser popularmente motivo de deboche.

É nesse primeiro minuto da canção que se começa a construir o tipo de ironia que segundo Beth Brait (2008) é o que permite que sejam descortinados certos aspectos culturais, sociais ou mesmo estilísticos que geralmente não são vistos em discursos mais sérios e que em geral são tratados com menos criticidade. A autora ressalta que o humor não está necessariamente a serviço do riso, mesmo que essa seja uma consequência inevitável e que a ironia não é necessariamente cômica ${ }^{4}$. É justamente esse tipo de humor e ironia que encontramos em Maria da Vila Matilde, um humor que não ri, apenas constrói imagens cômicas como estratégia de chamar a atenção para assuntos urgentes como a violência doméstica.

\footnotetext{
${ }^{4}$ Fazendo uma distinção entre palavras do mesmo campo semântico, tais como ironia e riso, Beth Brait, baseada em diversos estudiosos, traz o riso como fenômeno fisiológico e o cômico como uma construção da linguagem (2008).
} 
A seguir vem a segunda parte da canção, é nessa estrofe que temos acesso ao contexto socioeconômico do agressor, pois a personagem diz que quando o samango (gíria utilizada para se referir a policiais) chegar, além de apresentar a prova do crime: "Eu mostro o roxo no meu braço", também irá delatar para a polícia as maneiras escusas pelas quais seu companheiro se utiliza para ganhar dinheiro: "Entrego teu baralho/ Teu bloco de pule/ Teu dado chumbado". Podemos perceber nesses três versos, que se trata de uma pessoa com conceitos de ética deturpados ou inexistentes, pois além de praticar violências contra a mulher, tem sua renda financeira advinda de jogos corrompidos: "Teu dado chumbado". Ou seja, ganha dinheiro à medida que trapaceia, engana as pessoas. Trata-se de alguém que coloca suas vontades e seu conforto acima dos homens e da lei.

No sexto e sétimo versos "Ponho água no bule/ Passo e ainda ofereço um cafezin", o tom de deboche da estrofe se acentua. Começa com uma gradação de denúncias em que a personagem vai elencando os delitos cometidos pelo agressor e a partir do sexto verso, temos uma quebra dessa gradação para dar espaço a um clima amistoso e cordial entre a personagem e os policiais. Ao observarmos essa estrofe, percebemos que ela foi construída por meio de oposições, as imagens que nela se apresentam não seguem a sequência linear a qual estamos acostumados socialmente. À luz de Volochínov (2013), constatamos que essa contraposição configura a ironia que atravessa toda a canção. Tal gesto, de servir café para os policiais como se esses fossem amigos em um dia de visita, demonstra a posição adotada por Maria da Vila Matilde nessa discussão, ao tomar tal atitude, a personagem, ao mesmo tempo em que trata com firmeza seu agressor, mostra total segurança no controle da situação, aparentando, até certo ponto, tranquilidade.

Com relação aos aspectos rítmicos-melódicos, notamos que segue indissoluvelmente o tom da canção de forma a reforçar os efeitos de sentido propostos tanto pela letra, quanto pela entoação de Elza Soares. O sample que, no primeiro minuto, marca o tom grave da canção, agora é cessado para dar lugar ao baixo que, conjunto à voz de Elza no primeiro verso "E quando o samango chegar", cria o clima de suspense que marca o início da estrofe, como se a personagem estivesse brincando com os sentidos de seu interlocutor, ou quisesse deixá-lo apreensivo com o que estaria por vir.

Após a repetição do estribilho, já com todos os elementos musicais da canção, a segunda estrofe é introduzida. Estilisticamente essa é igual à primeira, há uma breve suspensão na melodia para que a voz de Elza Soares seguida do baixo crie o clima de suspense para a armação da cena seguinte. Dessa vez, no porvir vingativo, entra a figura 
da mãe do agressor e novamente o tom da hipotética conversa via telefone é amistoso. $\mathrm{O}$ eu-lírico afirma que quando a mãe ligar irá "caprichar no esculacho", falando de todos os defeitos do filho dela - ser "mimado", "cheio de dengo", "mal acostumado", não ter "nada no quengo" 5 e não ter uma atuação sexual satisfatória. Fazendo um breve levantamento do léxico apresentado nessa estrofe, percebemos que pertencem ao campo semântico do egoísmo e do egocentrismo. Se na primeira estrofe conhecemos o lado trapaceiro, de alguém que está acostumado a enganar os outros, nessa, em tom de intimidade, temos acesso a traços da personalidade desse agressor que indicam que essa é uma pessoa que apenas se preocupa com seu bem-estar, está - mal - acostumado a ser tratado com mimos e tenta obter aquilo que deseja por meio de manhas, além de não ter juízo ou responsabilidade, ou seja, alguém que costuma agir por impulso. Tais lexemas pertencem ainda ao campo semântico da infantilidade, pois, geralmente, são palavras utilizadas para descrever uma criança. Dessa forma, podemos percebê-lo como uma pessoa que ainda não passou completamente pelo processo de amadurecimento que se espera de uma pessoa adulta.

A partir de um processo interativo - locutor, interlocutor, espaço/tempo, horizonte valorativo -, assumimos uma atitude responsiva com relação à canção, notamos sob uma perspectiva dialógica que esse é um "discurso sobre o mundo que se funde com o discurso confessional sobre si mesmo" (BAKHTIN, 2008), ou seja, ao retratar seu relacionamento íntimo, o eu-lírico, ao dizer "deita, vira e dorme rapidinho", reflete a situação de incontáveis mulheres que permanecem em seus relacionamentos mesmo estando insatisfeitas em vários aspectos da vida conjugal. Nos campos espaço-temporal e valorativo, observamos que esse é um comportamento machista de subordinação da mulher que atravessa décadas e persiste até os dias de hoje, pois, como explicitado por Simone De Beauvoir (2016), nos anos de 1940, o casamento ainda é o destino tradicionalmente oferecido à mulher como uma forma de reconhecimento social carregado de positividade.

Por meio da Teoria do Humor, de Mikhail Bakhtin (2008), podemos pensar que tipo de humor constitui Maria da Vila Matilde. Pela abordagem histórica do autor russo, vimos que na Idade Média o riso assumiu um caráter libertador; agindo como forma de esclarecimento de mundo; que tornava tudo o que era temível em cômico, mas que, no

\footnotetext{
${ }^{5}$ Quengo é uma gíria utilizada para se referir à cabeça. Nesse contexto, equivale a "não ter juízo".
} 
entanto, não se misturava com o sério ${ }^{6}$. É no Renascimento que o cômico esforça-se para entrar em todas as esferas da vida ideológica, porém, encontra dificuldades devido a fatos históricos como a monarquia absolutista e a expressão ideológica na filosofia racionalista e na estética do classicismo, que empregavam um tom sério e autoritário, dessa forma, a partir desse período o riso passa por um processo de degradação. Até que no século XVIII torna-se vil e desprezível. No romantismo, período em que era bastante aplicada a visão subjetiva do mundo, o aspecto regenerador e positivo do riso reduz-se ao mínimo, então, o riso é eliminado e transforma-se em ironia e sarcasmo.

O humor que atravessa a canção é ainda esse humor libertador que permite o esclarecimento de mundo, pois as imagens cômicas não são construídas aleatoriamente, mas de forma dialógica, refletindo nesse discurso as valorações sociais presentes no nosso cotidiano. Embora achemos graça em ver um homem fugindo de um cachorro, as imagens que se seguem mesmo cantadas em igual tom de deboche revelam também um tom sarcástico, de alguém que emite uma entoação quase comemorativa e alegre ao dizer que vai mostrar o "roxo no braço" para a polícia. Se pensarmos que a palavra é carregada de valorações sociais e que na enunciação o sujeito revela sua ideologia e ou a ideologia de seu contexto social, mesmo que por meio de ironia (VOLOCHÍNOV, 2013), observaremos que o humor e o sarcasmo estão repletos de crítica e consciência social. Assim, no conjunto da canção notamos o tom de ambiguidade, pois, apesar de estar em situação de confronto, o eu-lírico mantém-se tranquilo para tomar café com os policiais e suficientemente à vontade para "esculachar" seu agressor para a mãe dele.

Essa ambiguidade no posicionamento da personagem é característica ao contexto sócio-histórico atual. De acordo com os estudos de Simone de Beauvoir (2016), o casamento se configura sob aspectos diferentes para o homem e para a mulher, apesar de ambos serem necessários um ao outro, essa necessidade não gera reciprocidade, pois o homem é visto socialmente como um indivíduo completo e autônomo e à mulher é imposta (socialmente) a obrigação de "dar filhos", cuidar da casa e atender as necessidades sexuais do marido. Embora a condição econômica da mulher tenha evoluído, ainda hoje vemos que há resquícios desse casamento tradicional. Em tempos remotos, em que a condição da mulher era de total submissão e que o homem tinha plenos direitos sobre sua esposa, essa canção não seria possível, pois em toda enunciação deve-

\footnotetext{
6 "O mundo infinito das formas e manifestações do riso opunha-se à cultura oficial, ao tom sério, religioso e feudal da época” (BAKHTIN, 2008).
} 
se levar em consideração o interlocutor e o contexto histórico e social (BAKHTIN, 2016). Somente em 22 de setembro de 2006, entrou em vigor a Lei 11.340, conhecida popularmente como "Lei Maria da Penha"; com esse dispositivo foi possível uma maior eficácia na prevenção e na punição de crimes de violência doméstica. Atualmente, além da Lei Maria da Penha, há uma maior conscientização social com relação às causas de gênero, as pautas de violência contra mulheres estão bem mais difundidas e atingem cada vez a um número maior de pessoas. Dessa forma, a canção, ambiguamente marcada pela comicidade, é na verdade um brado sério e contundente contra a violência doméstica e violência de gênero de modo geral; é também, antes de tudo, um incentivo e um alerta para que as mulheres denunciem seus agressores, pois não estão mais sozinhas nessa luta, agora - depois de séculos de negligência - há políticas públicas voltadas para que se pense a melhor forma de assegurar a vida de mulheres.

O refrão "Ce vai se arrepender de levantar a mão pra mim" é repetido ao final do estribilho e ao final de cada estrofe e funciona como um reforço da admoestação presente na totalidade da canção. Um reforço de que ela não irá tolerá-lo por mais tempo e que aquela situação não se repetirá. Sendo todo falante respondente de outros discursos com os quais teve contato, todo enunciado é constituído por discursos anteriores e discursos futuros ${ }^{7}$, assim, vemos que esse verso - que se diferencia formalmente dos outros por ser um verso bárbaro (13 sílabas poéticas), enquanto os demais são livres, compostos em sua maioria por versos em redondilha maior e redondilha menor - também se diferencia por sintetizar em uma oração o grito de guerra de tantas mulheres que assim como Maria da Vila Matilde não aceitam mais que a coloquem em posição passiva de subordinação ao marido. Essa atitude fica ainda mais evidente ao final da canção, quando à voz de Elza Soares juntam-se vozes de outras mulheres, o que subjetivamente sugere a imagem de várias mulheres gritando num só coro: "Cê vai se arrepender de levantar a mão pra mim"; deixando claro que o machismo não mais passará impune e as violências não mais serão naturalizadas.

Para arrematar, a canção termina em tom coloquial, a voz de Elza deixa de seguir o ritmo melódico da canção e em tom de prosa constrói a imagem da agressão física: "mão cheia de dedo/ Dedo cheio de unha suja"; para, de uma vez por todas, negá-la,

\footnotetext{
${ }^{7} \mathrm{O}$ discurso futuro constitui o enunciado do falante, pois esse está sempre atento ao seu público e suas possíveis respostas, o que dependendo do contexto pode fazer toda a diferença no discurso do enunciador. (BAKHTIN, 2016),
} 
reafirmando que não vai admitir que tal situação aconteça com ela: "E pra cima de mim? Pra cima de moi?/ Jamais, Mané!".

Apesar de refletir um discurso de mulheres conscientes de que podem ocupar os espaços públicos e privados se e como quiserem, mulheres que sabem que são donas de seus próprios corpos e vidas e que não têm obrigação de atender a nenhuma expectativa de gênero, esse ainda não é um discurso hegemônico. Muitas mulheres ainda se encontram em situação de violência sem perspectiva de solução para seus problemas, embora a Lei Maria da Penha tenha sido um grande passo, ainda há muito o que fazer para salvaguardar de fato a vida das mulheres. Sobre o empoderamento feminino, Angela Davis (DAVIS, 2017, p. 22) afirma que "o empoderamento das massas de mulheres deste país nunca será alcançado enquanto não tivermos êxito em deter a maré de racismo". A essa fala, além do racismo, devemos acrescentar todas as questões urgentes de adversidades vividas por mulheres, nos atentando para o fato de que somos muitas e somos plurais. Nesse sentido, Maria da Vila Matilde é uma canção de extrema importância e bastante necessária para que o debate sobre questões de gênero possa ser cada vez mais acessível, pois "de todas as formas de arte (...) a música atuou como a principal catalisadora no despertar da consciência social da comunidade" (DAVIS, 2017, p. 167).

\section{Referências}

BAKHTIN, M. A cultura popular na Idade Média e no Renascimento: o contexto de Rabelais. Tradução: Yara Frateschi Vieira. 6. ed. São Paulo: Hucitec, 2008.

BAKHTIN, M. Gêneros do Discurso. Tradução: Paulo Bezerra. São Paulo: Editora 34, 2016.

BEAUVOIR, S. O segundo sexo: a experiência vivida. Tradução: Sérgio Milliet. 3. ed. Rio de Janeiro: Editora Nova Fronteira, 2016.

BRAIT, B. Ironia em perspectiva polifônica. 2. ed. Campinas: Editora da UNICAMP, 2008.

CAMARGO, Z. Elza. Rio de Janeiro: LeYa, 2018.

CRISTIANE SERRA. Garrincha e Elza Soares: Paixão, Futebol e Música, ao extremo. Disponível em: https://crissserra.wordpress.com/2009/06/25/garrincha-e-elza-soarespaixao-futebol-e-musica-ao-extremo. Acesso em: 30 mar. 2020.

DAVIS, A. Mulheres, cultura e política. São Paulo: Editora Boitempo, 2017. 
PERcursos Linguísticos • Vitória (ES) •v. 10 •n. 25 • 2020 • ISSN: 2236-2592 •

Dossiê: Discursos de resistência e corpos (re)existentes

RODA VIVA. Roda Viva - Elza Soares. [São Paulo]: Roda Viva, 2012. 1 vídeo (1h). Disponível em: https://www.youtube.com/watch?v=8ko447IATMk\&t=547s. Acesso em: 30 mar. 2020.

SOARES, E. A Mulher do Fim do Mundo. São Paulo: Selo Circus, 2015.

VOLOCHÍNOV, V. N. A palavra na vida e a palavra na poesia: introdução ao problema da poética sociológica. In: VOLOCHÍNOV, V. N. Tradução: João Wanderley Geraldi. A construção da Enunciação e Outros Ensaios. São Carlos: Pedro \& João editores, 2013. cap, 7. p. 71-100.

WAISELFISZ, J. J. Mapa da Violência 2015: Homicídio de mulheres no Brasil. Brasília: OPAS-OMS/ONU Mulheres/SPM, 2015. 